\title{
Adopting a New Marking and Reporting System (MaRS) at Faculty Level: A Survey of Lecturers' Level of Readiness and Acceptance
}

\author{
Syafiqah Johan Amir Johan ${ }^{1,}$, Zulaikha Khairuddin ${ }^{1}$, Salina Sabri ${ }^{1}$, Fairuz Husna Mohd \\ Yusof $^{1}$, Fatin Fatinah Shamshul Bahrn ${ }^{1} \&$ Othman Ismail ${ }^{1}$ \\ ${ }^{1}$ Akademi Pengajian Bahasa, Universiti Teknologi MARA Shah Alam, 40450 Shah Alam, \\ Selangor, Malaysia \\ *Corresponding author: Akademi Pengajian Bahasa, Universiti Teknologi MARA Shah Alam, \\ 40450 Shah Alam, Selangor, Malaysia. Tel: 60-3-5544-2400. E-mail: syafiqah@uitm.edu.my
}

Received: September 24, 2021 Accepted: October 20, 2021 Published: November 12, 2021

doi:10.5296/ije.v13i4.19047ＵRL: https://doi.org/10.5296/ije.v13i4.19047

\begin{abstract}
At the end of each semester, academic and administrative staff of a faculty have to analyse students' results for a myriad of factors such as calculating performance of students and lecturers, and for the university's senate confirmation. Unfortunately, many relevant personnel at the faculty level lack the clearance to access students' results directly. To circumvent this issue, individual lecturers were required to print out and submit hardcopies of students' results and channel the data to relevant personnel. When the Covid-19 pandemic hit and lecturers were unable to submit the hardcopies, the faculty had to find an alternative. The introduction of the Marking and Reporting System (MaRS) marks a change from manual hardcopy submission of results following travel restrictions necessitated by the Malaysian government during the Covid-19 pandemic. As with any technological shift and innovation, the level of readiness and acceptance of academic and administrative staff at a faculty must be examined. This paper uses the Technology Acceptance Model (TAM) (Davis, 1986; Davis, Bagozzi \& Warshaw, 1989) to determine the level of readiness and investigate the level of acceptance among academic and administrative staff in using MaRS via a questionnaire. The findings suggest that with adequate guidance and assistance, the respondents were positive towards using MaRS as the system offers advantages to them such as being cost effective, environmentally friendly, and more convenient in recording students' results. In short, the respondents are ready and willing to use MaRS to manage students' results despite facing some difficulties in handling the system, because positively overcoming challenges will yield positive outcomes.
\end{abstract}

Keywords: technology acceptance model (TAM), google suite, assessment, results reporting, data analysis 


\section{Introduction}

\subsection{Background of Study}

Although all academic and administrative staff of a faculty in Malaysian universities have to process students' results at the end of each semester, the process might differ across universities and even across faculties at the same university. At the authors' faculty, academic staff have to analyse students' results after they have been submitted to the university's central grading system. Frustratingly, not all relevant personnel have access to the central grading system. As a result, a system has sprung up in place where individual lecturers had to print out their students' results and manually submit them to the faculty. This procedure resulted in a tedious process of analysis where relevant personnel, such as the the subject code Resource Person (RP) (i.e. the person in charge or "owners" of a subject code), coordinators, and assistant registrars (ARs), need to manually analyse numbers off thousands of printed pages.

To make matters worse, when the Covid-19 pandemic hit and lecturers were unable to submit the hardcopies, the faculty had to find an alternative. An ad hoc system of submission of results via Google Form (GF) was put in place. However, this simple procedure became confusing and frustrating as using GF resulted in redundant work processes since GF is an unsuitable platform for results submission. Moreover, due to differing levels of information technology (IT) competency, the authors experienced a situation where results submitted via GF became lost because the owner of the GF somehow became absurdly untraceable. Consequently, the authors and their colleagues had to submit the same results again via Google Sheets (GSheets) and/or Google Doc (GDoc) depending on the preferences and IT competency level of individual RPs, on top of a compulsory new GF link. Moreover, as Malaysia broke the daily highest number of reported Covid-19 cases multiple times throughout August 2021, a few lecturers contracted the virus and some even required hospitalisation (WHO, 2021). While unmarked tests and assessments could be reassigned to another lecturer, problems arose where marked assessment scores from the earlier part of the semester became inaccessible. In one case, a lecturer was hospitalised and required oxygenation during the marks reporting period and was therefore unable to share the password of the computer where the student marks were kept. The lecturer has happily recovered, but the incident drives home the realisation that in today's uncertain times, it would be prudent for the RP to have access to their lecturers' score sheets throughout the semester.

While the abrupt shift brought about by the Covid-19 pandemic has caused much confusion and stress (Choong, 2020; Marinoni et al., 2020; Rashid \& Yadav, 2020), the pandemic is not completely devoid of positive outcomes. Firstly, it reveals the archaic nature of the grade reporting method in place. Secondly, and more importantly, the pandemic acted as the catalyst that shifted the paradigm of the world to be more open and receptive to the incorporation of technology (Chung et al., 2020; Khadija Alhumaid et al., 2020; Muhammad Fuad et al., 2020; Yew \& Tan, 2020). For instance, reporting students' grades on GF and GSheet was inconceivable to the faculty in 2019, but the pandemic lockdowns, which started 
on the 18th of March 2020 in Malaysia (Ho, 2020), necessitated change and the shift towards a more technology-friendly education system duly took place (Vasudevan et al., 2021). Building on that momentum of change, the authors of this paper built an integrated Marking and Reporting System (MaRS) using GSheets and Google Drive (GD).

\subsection{Statement of the Problem}

At the end of each semester, academic and administrative staff of a faculty in a Malaysian university have to analyse students' results for a myriad of factors such as calculating performance of students and lecturers, and for the university's senate confirmation. Ideally, the marks and grades submitted to the university's grade reporting system are accessible to related personnel who can then extract the relevant data. Unfortunately, many relevant personnel at the faculty level such as Course or Programme Coordinators, RPs, Faculty Representatives, and ARs lack the clearance to access student results directly. To circumvent this issue, individual lecturers were required to print out and submit hardcopies of student results to the RPs who will then tabulate the data, analyse it, and channel the data and analyses to the other relevant personnel.

This method has two obvious drawbacks. Firstly, the RPs have to manually extract and tabulate data from so many individual class reports. As we are a servicing faculty (i.e. students from all faculties can subscribe to our courses) where a subject code can run up to 166 classes for more than 4,000 students, the manual process of analysis can be troublesome and inefficient. Moreover, the process is vulnerable to human error and some RPs have reported experiencing anxiety while analysing the results. Secondly, the traditional style of reporting incurred high costs financially and environmentally. Since each lecturer is required to submit two copies of the result reports per subject code, our faculty is estimated to have spent RM6,720 per semester for this purpose only. This figure is generated from the most conservative rates that neglect reprints and misprints, not to mention that the high consumption of paper runs counter to our university's green policies. As such, this study seeks to find out the level of readiness and acceptance among the academic and administrative staff within our faculty who used the newly introduced MaRS, which was deployed for the first time on the 6th of August 2021.

\subsection{Objectives of the Study}

This study attempts to investigate the level of readiness and acceptance of technology in education among the academic and administrative staff of a faculty in a Malaysian university. For the purpose of this study, a questionnaire is used to gauge their readiness and acceptance to using MaRS in reporting students' results.

As such, the two objectives of this study are:

1.3.1 To determine the level of readiness among the lecturers in using MaRS.

1.3.2 To investigate the level of acceptance among the lecturers in using MaRS. 
1.4 Research Questions

In order to achieve the objectives above, this study will attempt to answer the following research questions:

1.4.1 RQ1: What is the level of readiness among the lecturers in using MaRS?

1.4.2 RQ2: What is the level of acceptance among the lecturers in using MaRS?

\subsection{Significance of the Study}

To overcome the above issues, the authors of this study came up with MaRS for the academic and administrative staff of the faculty. At its core, MaRS comprises a marking sheet template and an RP sheet. A subject code's RP will customise the marking sheet template to the needs of their code. The template will then be auto-generated for each lecturer listed on the subject code's RP sheet. Data entered into a personalised marking sheet will then be captured by the RP sheet. MaRS overcomes the stated problems by utilising the built-in features of GSheet to generate real-time analysis of data collected and visual representation of said data for easy reporting. The security features of the Google environment allow the RP to limit viewing and editing access to relevant personnel only. In addition, being fully online allows MaRS to capture data instantaneously without having to be downloaded and reuploaded. Besides, using MaRS since the start of a semester would allow a smoother transition in cases where a lecturer becomes unavailable.

\section{Literature Review}

\subsection{Level of Acceptance of Technology in Education}

Today, 'technology' is no longer an alien word to people the world over. The use of technology in people's lives has become rather common and this is also the situation in the current educational field. According to Koral Gümüsoglu and Akay (2017), educators were starting to accept the use of technology in the classroom. This means that educators are well-aware of the fact that using technology is a necessity in education and it is no longer an optional teaching method. This is because educators have now acknowledged that they could help students learn better using technology, for instance in using collaborative learning strategies that integrate technology in the lessons (Asghar et al., 2021). Interestingly, Hamdani (2019) noted that the educators in one of the public universities in Tehran, Iran thought that the existence of technology was not useful even though they said that it was easy to be used. Indirectly, it can indicate that some educators are still resistant to using technology in doing their work. However, due to the recent Covid-19 pandemic, the stakeholders in education such as the lecturers, the students, and even the management staff are required to use technology and acceptance of the incorporation of technology in the classroom has become more positive (Chung et al., 2020; Khadija Alhumaid et al., 2020; Muhammad Fuad et al., 2020; Yew \& Tan, 2020).

The use of technology among educators is not only limited to the classroom setting, but it is 
also utilised in managing their other duties such as managing their e-portfolios and students' marks as well as compiling students' assignments (Jere, 2020). Even before the Covid-19 pandemic, Balash et al. (2011) mentioned that the faculty members from one of the public universities in Malaysia stated that they would be delighted to use technology in completing their tasks. This is because they felt that with technology, they could improve their productivity. It is interesting to note that the acceptance of using technology in education is not just for tertiary level, but also other educational levels. Hong et al. (2021) revealed that even preschool teachers were accepting the use of technology because they could complete their tasks easily with the help of technological tools. At the same time, they perceived that technology was useful for them in terms of managing their workload. Nonetheless, some educators mentioned that new methods and ways to handle a job would always entail challenges and difficulties such as learning to deal with technological tools or software (Oke \& Fernandes, 2020). That is why innovations that emerge in the education sector need to meet the needs of its stakeholders and inventors need to lessen and reduce the challenges that users might face (Hong et al., 2021). Hence, any piece of technology introduced to educators, students, policy makers, and the management needs to ease the stakeholders' workloads. Moreover, the tools and software introduced should be user-friendly as it will lessen the stress in using the technology. Thus, even though educators accept that the use of technology in their life as an educator would make their work easier, they still need to be assisted in handling the tools (Jere, 2020). In other words, it can be said that educators are slowly accepting and learning to use technology in completing their tasks.

\subsection{Level of Readiness of Technology Adoption in Education}

Ever since the pandemic Covid-19, people's readiness to technology use has been an international research interest. Whether the world is ready or not, the global pandemic has greatly accelerated the importance of technology in all aspects of everyday life, especially in education. In a study conducted by Mohamad Alakrash and Abdul Razak (2020), the results showed that the participants of their study were willing and ready to use technology in learning. The findings of this study also indicated that although the participants lacked the knowledge to apply technology into learning and may be hampered by a lack of equipment, they were mentally ready to incorporate technology into their learning journey, especially amidst a global pandemic. It can safely be said that the educational field is made up of highly-educated people, and these people are generally more accepting of changes. The findings from a study by Rojas-Méndez et al. (2017) confirm this. The results of their study demonstrated that men, the younger generation, and higher-educated people are more likely to be ready to adopt technology in their social and professional life. However, the same study also pointed out that women, the older generation, as well as lower-educated people tend to be quite apprehensive about the application of technology in various aspects of their life. As such, a certain degree of guidance and assistance is needed to ensure these groups' ease and readiness to technology adoption.

The success of using technology in all aspects, be it by students, educators, and/or the management of a higher learning institution, is significantly enhanced with support provided by the higher learning institution. This is proven based on the findings from the study done 
by Linjawi and Alfadda (2018). Should the institution provide its students and staff members with good internet connection, access to various web-based tools, and software and applications, the readiness to technology adoption is more positive. A study conducted by Asiroglu and Koc Akran (2018) also confirmed this as the participants in their study felt more confident and ready to apply technology into their teaching when and if they have the required skills and are familiar with the programme in question. The findings in a study by El Alfy et al. (2016) further confirmed this notion and indicated that positive attitudes towards technology would increase the readiness of educators and instructors. The Technology Acceptance Model (TAM) developed by Fred Davis in 1986, suggested that users would feel ready to use technology when these factors are in play: perceived usefulness (PU) and perceived ease of use (PEOU). The results in a study conducted by Rafiee and Abbasian-Naghneh (2019) demonstrated that these two variables, i.e. PU and PEOU, are two important factors in e-learning readiness in second language (L2) learning. As such, a web-based tool, be it for learning or for the management of a higher learning institutions, that is user-friendly and comes with human support to decrease the fear of technology, albeit virtually, is very highly likely to increase users' readiness to the application of technology in this high-paced and technologically advanced environment.

\section{Methodology}

\subsection{Research Design}

This study utilised a fully quantitative approach study because it involved both dependent and independent variables. The authors chose quantitative approach because this approach where the researchers will quantify and analyse dependent and independent variables and report the results in numerical data (Apuke, 2017). Moreover, this study used descriptive research design. Loeb et al. (2017) mentioned that descriptive research is considered as an informative design where it is relevant to understand a basic phenomenon.

\subsection{Population and Sampling Technique}

MaRS is a homegrown system built to address specific issues faced by one faculty at one of the public universities in Malaysia. The population of this study was about 200 academic and administrative staff of that particular faculty who utilised MaRS during the reporting of assessments results. With 200 academic and administrative staff as the population, this study should have 132 samples based on Krejcie and Morgan's (1970) sample size table. A total of 133 usable responses were received from the academic and administrative staff.

\subsection{Instrumentation}

This study utilised a questionnaire as it is used in most quantitative research for it collects more reliable information (Roopa \& Ran, 2012). The questionnaire was adapted from Weng et al. (2018) to ensure its validity. The adapted questionnaire obtained the Cronbach Alpha ( $\alpha$ $=.964)$ and therefore is reliable. There were 5 parts and 21 items in the questionnaire consisting of: 
Part A: Demographic Details

Part B: Perceived Usefulness

Part C: Perceived Ease of Use

Part D: Attitude toward Using

Part E: Intention to Use

\subsection{Methods of Data Collection and Analysis}

Data collection was done by distributing the questionnaire via the official communication channel of the faculty. The authors periodically reminded the respondents to complete the questionnaire within a two-week time frame before analysing the collected data using SPSS v27. The data were then portrayed in mean and standard deviation in the form of tables.

\section{Discussion}

\subsection{RQ 1: What is the Level of Readiness among the Lecturers in Using MaRS?}

Table 1. Perceived Usefulness

\begin{tabular}{lcc}
\hline & Mean & Std. Deviation \\
\hline $\begin{array}{l}\text { Using the APB Exam Reporting System in the reporting of results } \\
\text { helps me to check borderline cases (e.g. 59, 64). }\end{array}$ & 1.90 & \\
$\begin{array}{l}\text { Using the APB Exam Reporting System enhances my understanding } \\
\text { of Google Sheet and other web-based Google Docs Editor Suites. }\end{array}$ & 3.79 & .835 \\
$\begin{array}{l}\text { I find the APB Exam Reporting System useful during the reporting of } \\
\text { results analysis. }\end{array}$ & 4.28 & .801 \\
$\begin{array}{l}\text { Using the APB Exam Reporting System makes it easier to catch } \\
\text { errors in individual students' marks. }\end{array}$ & 3.62 & .974 \\
\end{tabular}

Table 1 portrays respondents' perception towards the usefulness of using the new exam reporting system introduced at the faculty level, MaRS. The highest mean score is obtained by 'I find the APB Exam Reporting System useful during the reporting of results analysis.' with a mean of $4.28(\mathrm{SD}=.801)$ and followed by 'Using the APB Exam Reporting System in the reporting of results helps me to check borderline cases (e.g. 59, 64).' with a mean score of 3.90 ( $\mathrm{SD}=1.072)$. Next, the mean scores for 'Using the APB Exam Reporting System enhances my understanding of Google Sheet and other web-based Google Docs Editor Suites.' and 'Using the APB Exam Reporting System makes it easier to catch errors in individual students' marks.' are $(\mathrm{M}=3.79, \mathrm{SD}=.835 ; \mathrm{M}=3.62, \mathrm{SD}=.974)$ respectively. This shows that the respondents indicated that they agree that the new system introduced for reporting students' results is useful. 
Table 2. Perceived Ease of Use

\begin{tabular}{lcc}
\hline & Mean & Std. Deviation \\
\hline APB Exam Reporting System helps me to become more skillful in & 3.71 & .918 \\
my computer skills. & & .848 \\
I find it easy to apply/use the APB Exam Reporting System in the & 4.09 & \\
scoring of my students' marks next semester. & & .824 \\
Using the APB Exam Reporting System is easy and understandable. & 4.14 & .896 \\
Using the APB Exam Reporting System is more flexible than & 4.12 & \\
traditional methods.
\end{tabular}

Table 2 illustrates how the respondents perceived the ease of use when using the new system for results reporting. The highest mean score is gained by 'Using the APB Exam Reporting System is easy and understandable.' with a mean score of $4.14(\mathrm{SD}=.824)$. Next, the mean score for 'Using the APB Exam Reporting System is more flexible than traditional methods.' and ' $I$ find it easy to apply/use the APB Exam Reporting System in the scoring of my students' marks next semester.' are $(\mathrm{M}=4.12, \mathrm{SD}=.896 ; \mathrm{M}=4.09, \mathrm{SD}=.848)$ respectively. The least mean score is attained by 'APB Exam Reporting System helps me to become more skillful in my computer skills.' with $3.71(\mathrm{SD}=.918)$. Based on the results, it can be seen that the respondents agree that it is easy to use the newly introduced system.

Table 3. Level of Readiness

\begin{tabular}{lcc}
\hline & Mean & Std. Deviation \\
\hline Level of Readiness & 4.00 & .705 \\
\hline
\end{tabular}

Table 3 shows the level of readiness among respondents in using technology in general and the new system specifically. The mean score of the respondents' level of readiness is 4.00 $(\mathrm{SD}=.705)$ which means the respondents agree that they are ready to use technology in managing the students' results and in handling tasks that are related to the workplace.

\subsection{RQ 2: What is the Level of Acceptance among the Lecturers in Using MaRS?}

Table 4 depicts the attitude towards using MaRS among the respondents. The highest mean score recorded is 4.32 by 'I think it is valuable to use the APB Exam Reporting System as a system to report students.' results because it is cost saving and environmentally friendly.' $(\mathrm{SD}=.784)$. This is followed by 'I think it is a good change to use the APB Exam Reporting System in reporting students' results.' with a mean of 4.23 ( $\mathrm{SD}=0.858)$. Next, the mean score for 'Using the APB Exam Reporting System as a platform to report students' results is easy.' and 'Using the APB Exam Reporting System is favourable' are $(\mathrm{M}=4.20, \mathrm{SD}=.857 ; \mathrm{M}=4.11$, $\mathrm{SD}=.873)$ respectively. The lowest mean score of 3.80 and $\mathrm{SD}=0.933$ are recorded by 'The 
APB Exam Reporting System has a positive influence on me to start keeping track of students' assessments, scores and results using an online method/platform.' These results show that the respondents are positive towards using MaRS as it benefits them in various ways.

Table 4. Attitude towards Using

\begin{tabular}{lcc}
\hline & Mean & Std. Deviation \\
\hline $\begin{array}{l}\text { Using the APB Exam Reporting System as a platform to report } \\
\text { students' results is easy. }\end{array}$ & .20 & .857 \\
Using the APB Exam Reporting System is favourable. & 4.11 & .873 \\
The APB Exam Reporting System has a positive influence on me to & 3.80 & .933 \\
start keeping track of students' assessments, scores and results using & & \\
$\begin{array}{l}\text { an online method/platform. } \\
\text { I think it is valuable to use the APB Exam Reporting System as a }\end{array}$ & 4.32 & .784 \\
$\begin{array}{l}\text { system to report students' results because it is cost saving and } \\
\text { environmentally friendly. }\end{array}$ & \\
$\begin{array}{l}\text { I think it is a good change to use the APB Exam Reporting System in } \\
\text { reporting students' results. }\end{array}$ & & \\
\hline
\end{tabular}

Table 5. Intention to Use

\begin{tabular}{lcc}
\hline & Mean & Std. Deviation \\
\hline I intend to use the APB Exam Reporting System for the next semester. & 4.14 & .877 \\
I plan to use the APB Exam Reporting System from the first & 3.69 & 1.081 \\
assessment/beginning of the semester. & & \\
I would use the APB Exam Reporting System at all levels of reporting & 4.00 & .969 \\
(as a lecturer, as a resource person, as a faculty representative, at the & & \\
pre-JAF and JAF level). & & \\
I would love to use the APB Exam Reporting System for all codes. & 4.09 & .941 \\
I would love to use the APB Exam Reporting System to be more & 4.16 & .903 \\
efficient and productive when it comes to reporting of results analysis. & &
\end{tabular}

Table 5 displays the intention to use MARS in the future among the respondents. The highest mean score recorded was $4.16(\mathrm{SD}=0.903)$ for 'I would love to use the APB Exam Reporting System to be more efficient and productive when it comes to reporting of results analysis'. The next highest mean recorded is $4.14(\mathrm{SD}=.877)$ for ' $\mathrm{I}$ intend to use the APB Exam Reporting System for the next semester.'. Next, the mean score for 'I would love to use the APB Exam Reporting System for all codes.' and 'I would use the APB Exam Reporting System at all levels of reporting (as a lecturer, as a resource person, as a faculty representative, at the pre-JAF and JAF level).' are 4.09 and $4.00(\mathrm{SD}=.941$ and $\mathrm{SD}=.969)$ 
respectively. The lowest mean score, recorded by 'I plan to use the APB Exam Reporting System from the first assessment/beginning of the semester', is 3.69 ( $\mathrm{SD}=1.081)$. Based on the results, it can be seen that the respondents have high intention in using MaRS in the future.

Table 6. Level of Acceptance

\begin{tabular}{lrc}
\hline & Mean & Std. Deviation \\
\hline Level of Acceptance & 4.07 & .772 \\
\hline
\end{tabular}

Table 6 shows the level of acceptance among the respondents in using technology in general and the new system specifically. The mean score of the respondents' level of readiness is 4.07 $(\mathrm{SD}=.772)$ which means the respondents agree that they could accept using the system to manage the students' results and technology in handling tasks related to the workplace.

\section{Discussion}

\subsection{Summary of Findings}

In terms of perceived usefulness, the respondents agree that there are various benefits of MaRS that could be offered to them. This is probably because they had experienced handling the marks for two consecutive semesters which made it possible for them to compare. The analysis of students' marks was made easier and more accurate due to the systematic organisation of the system and the availability of the auto-calculation feature. Besides, borderline marks could be easily identified by the system instead of having to be done manually which is usually bound to result in human errors. This is supported by Long (2018) which stated that automation in a system helps to eliminate human errors and ensures accuracy every step of the way.

Next, the respondents agree that it is easy to use the newly introduced system. This is probably because the system is user-friendly and it is easy to comprehend and utilise. The interface was designed based on the existing university system which creates a sense of familiarity in terms of the 'look and feel' among the users. As stated by Jitnupong and Jirachiefpattana (2018), a user-friendly user interface helps users to carry out their tasks with efficiency, effectiveness, and satisfaction. In addition, before the implementation of MaRS, workshops were organised to explain the processes in using the system, including step-by-step instructions by the developers for lecturers. An infographic lecturer's guide was also provided for their reference. Once the system was launched, all academic and administrative staff were invited to attend any of the 20 sessions of the online clinics manned by trained facilitators in case they were to face any problems with the system.

Based on the results, the respondents were positive towards using MaRS as the system offers advantages to them such as being cost effective and environmentally friendly and being more 
convenient in recording students' assessment marks. The system also enables lecturers to key in their marks early in the semester rather than having to wait until the end of the semester for the system to be available, which may allow for a smoother transition in cases where a lecturer becomes unavailable. These reasons could lead to the high intention to use the system in the future based on the survey. As MaRS is perceived to be more efficient and productive in the analysis of results, the respondents also agree to have this system applied to all levels of reporting (as a lecturer, as a resource person, and as a faculty representative). This is probably because the built-in features of GSheet in MaRS generate real-time analysis of data collected and the visual representation of said data for easy reporting, which makes the system more convenient and preferred. As stated by Shah (2014), management information system creates opportunities for better accessibility to information, more efficient management and administration, reduction of workload, more efficient time management and improvement in the report quality.

In conclusion, the respondents are ready and willing to use the system to manage students' results despite facing some difficulties in handling the system, because positively overcoming challenges will yield positive outcomes. This is congruent to Godoe and Johansen's (2012) study in which they found out that actual use among users of a system was directly affected by perceived usefulness, but not by perceived ease of use.

\subsection{Conclusion}

Based on the study, it is evident that MaRS has assisted academic and administrative staff to ease the reporting and analysis of students' results, which in turn helps to lessen the burden of having to do the analysis manually and to remove redundant workflows. In addition, errors when tabulating results could be minimised significantly as the analysis is done automatically. Consequently, the work performance of the RPs, faculty representatives, and lecturers could be improved. Furthermore, social isolation due to Covid-19 has impacted the mental health of not only students, but also lecturers, primarily because of workload pressure and stress (Filho et. al., 2021). MaRS helps to diminish redundant workflows and reduce the stress level of lecturers, hence it is recommended that MaRS developers expand the system to be continuously used.

The respondents also agree that MaRS is environmentally friendly, cost-effective, and user friendly in analysing students' results. When academic and administrative staff do not have to use money to complete the process of result reporting, they would be able to spare money on technological tools that will help improve the students' learning process. This is also supported by research done by Saini and Al-Mamri (2019) which asserts that if utilised appropriately, technology is able to positively change the educational landscape. Additionally, MaRS has also proven to be eco-friendly, which aligns with the "Go Green" initiative introduced by the university. According to Iqbal and Ahmed (2015), to prevent forest degradation, introducing some alternatives in workplaces and academic places is vital. With the existence of MaRS, printing and reprinting of results is able to be fully avoided, which subsequently helps to reduce carbon footprint. It is recommended that MaRS developers continuously adjust and further improve their system to attract other faculties in the authors' 
university to use it in the future.

\subsection{Suggestions for Future Research}

Future studies can look into the factors that affect the level of readiness and level of acceptance among the lecturers in using the updated version of MaRS. Studies through qualitative interviews, focusing on RPs and faculty representatives, on top of lecturers, could also be conducted to gain better understanding of the issues revolving the reporting or analysis of students' results to assist MaRS developers in making further improvements to the system.

\section{References}

Alhumaid, K., Ali, S., Waheed, A., Zahid, E., \& Habes, M. (2020). COVID-19 \& Elearning: Perceptions \& Attitudes Teachers towards E-Learning Acceptance in the Developing $\begin{array}{llll}\text { Countries. } & \text { Multicultural } & \text { Education, } & \text { 100-115. }\end{array}$ https://doi.org/10.5281/zenodo.4060121

Apuke, O. D. (2017). Quantitative research methods: A synopsis approach. Kuwait Chapter of Arabian Journal of Business and Management Review, 33(5471), 1-8. http://dx.doi.org/10.12816/0040336

Asghar, M. Z., Barberà, E., \& Younas, I. (2021). Mobile learning technology readiness and acceptance among pre-service teachers in Pakistan during the COVID-19 pandemic. Knowledge Management \& E-Learning: An International Journal, 13(1), 83-101. https://doi.org/10.34105/j.kmel.2021.13.005

Asiroglu, S., \& Koc, A. S. (2018). The Readiness Level of Teachers in Science, Technology, Engineering and Mathematics Education. Universal Journal of Educational Research, 6(11), 2461-2470. https://doi.org/10.13189/ujer.2018.061109

Balash, F., Yong, Z., \& Abu, B. B. (2011). Acceptance level of faculty members in utilizing educational technology tools. International Journal of Information and Education Technology, 1(5), 360-364. https://doi.org/10.7763/IJIET.2011.V1.58

Choong, P. Y. (2020, May 8). Covid-19: Impact on the tertiary education sector in Malaysia. Retrieved from https://penanginstitute.org/wp-content/uploads/2020/05/IMPACT-ON-THE-TERTIARY -EDUCATION-SECTOR-IN-MALAYSIA.pdf

Chung, E., Subramaniam, G., \& Christ Dass, L. (2020). Online learning readiness among university students in Malaysia amidst Covid-19. Asian Journal of University Education (AJUE), 16(2), 45-58. https://doi.org/10.24191/ajue.v16i2.10294

El Alfy, S., Gómez, J. M., \& Ivanov, D. (2016). Exploring instructors' technology readiness, attitudes and behavioral intentions towards e-learning technologies in Egypt and United Arab Emirates. Education and Information Technologies, 22(5), 2605-2627. 
https://doi.org/10.1007/s10639-016-9562-1

Filho, W. L., Wall, T., Rayman-Bacchus, L., Misfud, M., Pritchard, D. J., Lovren, V. O., Farinha, C., Petrovic, D. S., \& Balogun, A. (2021). Impacts of COVID-19 and social isolation on academic staff and students at universities: a cross-sectional study. $B M C$ Public Health, 21(1213), 1-19. https://doi.org/10.1186/s12889-021-11040-z

Godoe, P., \& Johansen, T. S. (2012). Understanding Adoption of New Technologies: Technology Readiness and Technology Acceptance as an Integrated Concept. Journal of European Psychology Students, 3(1), 38. https://doi.org/ 10.5334/jeps.aq

Hamdani, M. (2019). Technology Acceptance in the Use of Social Networks by Teachers and Employees of Education Offices in Ahwaz. Turkish Online Journal of Educational Technology-TOJET, 18(1), 105-117. https://files.eric.ed.gov/fulltext/EJ1201798.pdf

Ho, K. D. T. (2020). Movement control as an effective measure against Covid-19 spread in Malaysia: An overview. Journal of Public Health: From Theory to Practice, 1-4. https://doi.org/10.1007/s10389-020-01316-w

Hong, X., Zhang, M., \& Liu, Q. (2021). Preschool Teachers' Technology Acceptance during the COVID-19: An Adapted Technology Acceptance Model. Frontiers in Psychology, 12, 1-11. https://doi.org/10.3389/fpsyg.2021.691492

Iqbal, M. H., \& Ahmed, F. (2015). Paperless campus: The real contribution towards a sustainable low carbon society. Journal of Environmental Science, Toxicology and Food Technology, 9(8), 10-17. https://doi.org/10.9790/2402-09811017

Jere, J. N. (2020). Investigating university academics behavioural intention in the adoption of e-learning in a time of COVID-19. South African Journal of Information Management, 22(1), 1-9. https://doi.org/10.4102/sajim.v22i1.1280

Jitnupong, B., \& Jirachiefpattana, W. (2018). Information System User Interface Design in Software Services Organization: A Small-Clan Case Study. MATEC Web of Conferences, 164(01006), 1-12. https://doi.org/10.1051/matecconf/201816401006

Koral Gümüşoğlu, E., \& Akay, E. (2017). Measuring technology acceptance level of teachers by using unified theory of acceptance and use of technology. International Journal of Languages' Education and Teaching, 5(4), 378-394. https://doi.org/10.18298/ijlet.2239

Krejcie, R. V., \& Morgan, D. W. (1970). Determining sample size for research activities. Educational and psychological measurement, 30(3), 607-610.

Linjawi, A. I., \& Alfadda, A. S. (2018). Students' perception, attitudes, and readiness toward online learning in dental education in Saudi Arabia: a cohort study. Advanced Medical Education Practice, 9, 855-863. https://doi.org/10.2147/AMEP.S175395

Loeb, S., Dynarski, S., McFarland, D., Morris, P., Reardon, S., \& Reber, S. (2017). Descriptive analysis in education: A guide for researchers (No. NCEE 2017-4023). Washington, DC: National Center for Education Evaluation and Regional Assistance. 
https://files.eric.ed.gov/fulltext/ED573325.pdf

Long, L. (2018, November 9). How the Right Automation Road Map Helps Overcome Human Error. Retrieved from https://www.forbes.com/sites/forbestechcouncil/2018/11/09/how-the-right-automation-r oad-map-helps-overcome-human-error/?sh=7f734bac647f

Marinoni, G., Van't Land, H., \& Jensen, T. (2020). The impact of Covid-19 on higher education around the world: IAU global survey report. International Association of Universities. Retrieved from https://www.iau-aiu.net/IMG/pdf/iau_covid19_and_he_survey_report_final_may_2020. pdf

Mohamad Alakrash, H., \& Abdul Razak, N. (2020). Towards the Education 4.0, Readiness Level of EFL Students in Utilising Technology-Enhanced Classroom. International Journal of Innovation, Creativity and Change, 13(10), 161-182.

Muhammad, F., Farida, A., Edi, S., \& Ari, S. S. (2020). Exploring teachers' TPCK: Are Indonesian language teachers ready for online learning during the COVID-19 outbreak? Universal Journal of Educational Research, 8(11B), 6091-6102.

Oke, A., \& Fernandes, F. A. P. (2020). Innovations in teaching and learning: Exploring the perceptions of the education sector on the 4th industrial revolution (4IR). Journal of Open Innovation: Technology, Market, and Complexity, 6(2), 31. https://doi.org/10.3390/joitmc6020031

Rafiee, M., \& Abbasian-Naghneh, S. (2019). E-learning: development of a model to assess the acceptance and readiness of technology among language learners. Computer Assisted Language Learning, 1-21. https://doi.org/10.1080/09588221.2019.1640

Rashid, S., \& Yadav, S. S. (2020). Impact of Covid-19 Pandemic on Higher Education and Research. Indian Journal of Human Development, 14(2), 340-343. https://doi.org/10.1177/0973703020946700

Rojas-Méndez, J. I., Parasuraman, A., \& Papadopoulos, N. (2017). Demographics, attitudes, and technology readiness. Marketing Intelligence \& Planning, 35(1), 18-39. https://doi.org/10.1108/mip-08-2015-0163

Roopa, S., \& Ran, M. S., (2012). Questionnaire Designing for a Survey. The Journal of Indian Orthodontic Society 46(4), 273-277. http://dx.doi.org/10.5005/jp-journals-10021-1104

Saini, D. K., \& Al-Mamri, M. R. S. (2019). Investigation of technological tools used in education system in Oman. Social Sciences \& Humanities Open, 1(1), 1-10. https://doi.org/10.1016/j.ssaho.2019.100003

Shah, M. (2014). Impact of management information systems (MIS) on school administration: What the literature says. Procedia-Social and Behavioral Sciences, 116, 2799-2804. https://doi.org/10.1016/j.sbspro.2014.01.659 


\section{Macrothink}

International Journal of Education ISSN 1948-5476 2021, Vol. 13, No. 4

Vasudevan, G., Aw, S. W. K., \& Paramasivam, G. (2021). Challenges and the impact of Covid-19 pandemic on higher education universities in Klang Valley, Malaysia. International Journal of Advanced Research in Education and Society, 3(3), 16-23. Retrieved from https://myjms.mohe.gov.my/index.php/ijares/article/view/15067/7720

Weng, F., Yang, R. J., Ho, H. J., \& Su, H. M. (2018). A TAM-based study of the attitude towards use intention of multimedia among school teachers. Applied system innovation, 1(3), 1-9. http://dx.doi.org/10.3390/asi1030036

World Health Organisation (WHO) (2021). WHO Health Emergency Dashboard: Malaysia. Retrieved from https://covid19.who.int/region/wpro/country/my

Yew, K. K. W., \& Tan, K. H. (2020). ESL teachers' intention in adopting online educational technologies during Covid-19 pandemic. Journal of Education and e-Learning Research, 7(4), 387-394. https://doi.org/10.20448/journal.509.2020.74.387.394

\section{Copyright Disclaimer}

Copyright for this article is retained by the author(s), with first publication rights granted to the journal.

This is an open-access article distributed under the terms and conditions of the Creative Commons Attribution license (http://creativecommons.org/licenses/by/3.0/). 